\title{
Excessive production of mitochondrion-derived reactive oxygen species induced by titanium ions leads to autophagic cell death of osteoblasts via the SIRT3/SOD2 pathway
}

\author{
SIQIAN WANG ${ }^{1}$, JINGYUAN YANG $^{1}$, TINGTING LIN $^{2}$, SHENGBING HUANG $^{2}$, JIANFENG MA $^{2}$ and XIN XU ${ }^{1}$ \\ ${ }^{1}$ Department of Implantology, School and Hospital of Stomatology, Shandong University, Shandong Key \\ Laboratory of Oral Tissue Regeneration and Shandong Engineering Laboratory for Dental Materials \\ and Oral Tissue Regeneration, Jinan, Shandong 250012; ${ }^{2}$ Department of Prothodontics, School and \\ Hospital of Stomatology, Wenzhou Medical University, Wenzhou, Zhejiang 325027, P.R. China
}

Received August 3, 2019; Accepted April 4, 2020

DOI: $10.3892 / \mathrm{mmr} .2020 .11094$

\begin{abstract}
The incidence of peri-implant bone loss is high, and is a difficult condition to treat. Previous studies have shown that titanium ( $\mathrm{Ti}$ ) ions released from implants can lead to osteoblast cell damage, but the specific mechanisms have not been elucidated. The present study established a Ti ion damage osteoblast cell model. The levels of mitochondrion-derived reactive oxygen species (mROS) and autophagy, cell viability and the sirtuin 3 (SIRT3)/superoxide dismutase 2 (SOD2) pathway were examined in this model. It was found that $\mathrm{Ti}$ ions decreased osteoblast viability. Moreover, with increased $\mathrm{Ti}$ ion concentration, the expression levels of microtubule associated protein 1 light chain $3 \alpha$ (LC3) progressively increased, P62 decreased, autophagic flow increased and mROS levels increased. After the addition of an autophagy inhibitor Bafilomycin A1 and Mito-TEMPO, a mitochondrial antioxidant, the production of mROS was inhibited, the level of autophagy was decreased and cell activity was improved. In addition, with increased $\mathrm{Ti}$ ion concentration, the activity of SOD2 decreased, the acetylation level of SOD2 increased, the SIRT3 mRNA and protein expression levels decreased, and the activity of SIRT3 was significantly decreased. Furthermore, it was demonstrated that SIRT3 overexpression reduced the acetylation of SOD2 and increased the activity of SOD2, as well as reducing the production of mROS and the expression level of LC3, thus increasing cell viability. Therefore, the
\end{abstract}

Correspondence to: Dr Xin Xu, Department of Implantology, School and Hospital of Stomatology, Shandong University, Shandong Key Laboratory of Oral Tissue Regeneration and Shandong Engineering Laboratory for Dental Materials and Oral Tissue Regeneration, 44-1 Wenhua Xi Road, Jinan, Shandong 250012, P.R. China E-mail: 20442947@qq.com

Key words: titanium ion, osteoblasts, autophagy, mitochondrial reactive oxygen species, sirtuin 3 , superoxide dismutase 2 present results suggested that excessive production of mROS induced by Ti ions led to autophagic cell death of osteoblasts, which is dependent on the SIRT3/SOD2 pathway.

\section{Introduction}

Dental bone implants are frequently used for replacing missing teeth. The clinical success of bone implants is dependent on the successful integration of the biomaterial into regenerated bone tissue, which occurs via the adhesion, proliferation and differentiation of osteoblasts(1-4). The adhesion process is followed by the production of mineralized matrix directly on the surface of the biomaterial (1-4). However, it is estimated that $5-11 \%$ dental implants fail within $10-15$ years, which then must be removed $(5,6)$. The loss of a dental implant is generally attributed to peri-implant bone loss. Therefore, it is important to elucidate the mechanism of peri-implant bone loss and facilitate the understanding of osseointegration of implants in order to improve the success rate of clinical implantation.

Titanium (Ti) and its alloys are choice materials for dental implants due to the high biocompatibility and corrosion resistance properties (7). However, Ti implants can dissolve due to stress corrosion, galvanic corrosion and chemical corrosion in the oral environment, resulting in the precipitation of $\mathrm{Ti}$ ions (8). In vivo studies have demonstrated that the release of Ti ions into surrounding tissue, regional lymph nodes and internal organs can occur during or after implant placement (9-11). In a rabbit model based on synchrotron radiation $\mathrm{X}$-ray fluorescence, Ti ions were detected in bony tissues 12 weeks and 1 year after implant placement (12).

Ti ions released from dental implants play an important role in peri-implant complications, including bone loss via several mechanisms (13-15). Bitar and Parvizi (16) identified cytokine-mediated osteolytic changes caused by reactive oxygen species (ROS) intermediates and activation of the complement cascade as factors affecting bone metabolismin macrophages from mice in vitro. Mitochondria, as the power plant of cells, are the primary location of ROS production. However, to the best of our knowledge, the effect of Ti ions on 
mitochondria derived ROS (mROS) has not been previously studied in depth.

Therefore, the present study investigated the mechanism of Ti ion damage to osteoblasts, and the possible mechanism of increased mROS production.

\section{Materials and methods}

Cell culture. Osteoblastic cells were purchased from Lonza (Clonetics Normal Human Osteoblast Cell System). Cells were cultured in RPMI-1640 medium (Gibco; Thermo Fisher Scientific, Inc.) containing 10\% FBS (Gibco; Thermo Fisher Scientific, Inc.) and 1\% (v/v) penicillin/streptomycin (cat. no. P4333; Sigma-Aldrich; Merck KGaA) and incubated at a humidified atmosphere with $5 \% \mathrm{CO}_{2}$ at $37^{\circ} \mathrm{C}$. The culture medium was changed every 2 days. At 70-80\% confluency, adhered cells were detached using $0.25 \%$ trypsin/EDTA solution. Osteoblastic cells of passages 4-6 were used for the subsequent experiments. All experiments were performed three times.

Cell experimental protocol. The effect of Ti ions on autophagy in osteoblastic cells was evaluated. Cells were treated with $\mathrm{TiCl}_{4}$ (cat. no. 7550-45-0; Shanghai Aladdin Bio-Chem Technology Co., Ltd.) at different concentrations $(0,10,25$ and $50 \mu \mathrm{M})$ at $37^{\circ} \mathrm{C}$ for $24 \mathrm{~h}$. The cells were also treated with various concentrations $(0,10,25$ and $50 \mu \mathrm{M})$ of $\mathrm{TiCl}_{4}$ for $24 \mathrm{~h}$ with or without lysosomal inhibitor bafilomycin A1 (Baf-A1; $20 \mathrm{nM}$; Cell Signaling Technology, Inc.) at $37^{\circ} \mathrm{C}$ for $24 \mathrm{~h}$. The vehicle control used for each in vitro assay was $0.1 \%$ DMSO. The role of the sirtuin3 (SIRT3)/superoxide dismutase 2 (SOD2) pathway in osteoblasts was investigated.

Cell viability. Cell viability was analyzed using the Cell Counting Kit-8 (CCK-8) according to the manufacturer's instructions (cat. no. CK04; Dojindo Molecular Technologies, Inc.). Briefly, $1 \times 10^{4}$ cells were inoculated into 96 -well plates. After treatment, $90 \mathrm{ml}$ RPMI 1640 medium and $10 \mathrm{ml}$ CCK-8 solution were added to each well. The cells were then incubated at $37^{\circ} \mathrm{C}$ for $2 \mathrm{~h}$, and the absorption was measured at $450 \mathrm{~nm}$ using an Infinite M200 microplate reader (Tecan Group, Ltd.). Data are presented as percentages relative to the control.

Determination of mROS. After treatment, osteoblastic cells were incubated with culture medium containing $10 \mathrm{mM}$ MitoSOX (cat. no. M36008; Invitrogen; Thermo Fisher Scientific, Inc.) for $20 \mathrm{~min}$ at $37^{\circ} \mathrm{C}$. Osteoblastic cells were pre-incubated at $37^{\circ} \mathrm{C}$ with $10 \mathrm{mM}$ Mito-TEMPO (Sigma-Aldrich; Merck KGaA) for $2 \mathrm{~h}$ before the $24 \mathrm{~h} \mathrm{TiCl}_{4}$ exposure.The fluorescence intensity was analyzed with an Infinite M200 Microplate Reader (Tecan Group, Ltd.) at an excitation wavelength of $492 \mathrm{~nm}$ and an emission wavelength of $595 \mathrm{~nm}$. Cellular fluorescence intensity was expressed as fold-change relative to control.

Measurement of SOD2 enzyme activity. SOD2 enzymatic activity was assessed using a SOD1 and SOD2 assay kit (cat. no. S0103; Beyotime Institute of Biotechnology) according to the manufacturer's instructions. For quantification, one unit of SOD was defined as the amount of enzyme that inhibited the rate of nitro-blue tetrazoliumreduction observed in a blank sample by $50 \%$ (17). The SOD isoforms were identified by adding the SOD1 inhibitor A and B according to the manufacturer's instructions to inhibit SOD1 activity (i.e., to detect SOD2). The absorption at $450 \mathrm{~nm}$ was measured using an Infinite M200 microplate reader.

Plasmids and transfection. LV5-SIRT3 overexpression lentivirus were purchased from Yuxi Biotechnology Corporation (Fig. S1A). The transfection assay was performed according to the manufacturer's protocols. Osteoblastic cells were grown in DMEM (Gibco; Thermo Fisher Scientific, Inc.) with 20\% FBS (Gibco; Thermo Fisher Scientific, Inc.) on culture dishesat a humidified atmosphere of $5 \% \mathrm{CO}_{2}$ at $37^{\circ} \mathrm{C}$, and were infected with the lentivirus for $72-96 \mathrm{~h}$ (Fig. S1B). The lentivirus contained green fluorescent protein, which was visible in fluorescence microscopy. Cells were then washedwith DMEM (Gibco; Thermo Fisher Scientific, Inc.) and processed for subsequent experiments. Western blotting was used to show that transfection was successful (Fig. S1C).

Reverse transcription-quantitative PCR (RT-qPCR). TRIzol ${ }^{\circledR}$ (Invitrogen; Thermo Fisher Scientific, Inc.) was used to extract RNA from osteoblastic cells, and its concentration and purity were detected with a UV spectrophotometer. cDNA was synthesized using a Sensiscript RT kit (Thermo Fisher Scientific, Inc.). All reagents used for RT-qPCR to detect SIRT3 mRNA were obtained from Thermo Fisher Scientific, Inc. The following primer sequences were used: SIRT3 forward, 5'- GACATCCCGTACCCTGAAG-3; and reverse, 5'-AGCTGTTACAAAGGTCCCGT-3'; and GAPDH forward, 5'-CGAGAATGGGAAGCTTGTCA-3' and reverse, 5'-GACATCCCGTACCCTGAAG-3'. The reaction system consisted of $4 \mu 15 \mathrm{X}$ buffer $+1.5 \mu 1 \mathrm{MgCl}_{2}+0.5 \mu 1 \mathrm{dNTP}+0.8 \mu \mathrm{l}$ sense and antisense primers $+0.3 \mu \mathrm{l}$ Taq enzyme $+2 \mu \mathrm{l}$ cDNA template, $+0.4 \mu 1$ passive dye (SYBR Green; Thermo Fisher Scientific, Inc.) and $11.5 \mu \mathrm{l}$ water to $20 \mu \mathrm{l}$. The reaction conditions were: Initial denaturation at $95^{\circ} \mathrm{C}$ for $3 \mathrm{~min}$, followed by 35 cycles at $95^{\circ} \mathrm{C}$ for $30 \mathrm{sec}, 55^{\circ} \mathrm{C}$ for $20 \mathrm{sec}$ and $72^{\circ} \mathrm{C}$ for $20 \mathrm{sec}$; and a final extension step at $72^{\circ} \mathrm{C}$ for $10 \mathrm{~min}$. The dissociation curve was obtained and the $2^{-\Delta \Delta \mathrm{Cq}}$ method (18) was used to calculate the relative expression of mRNA.

SIRT3 activity. A fluorometric kit (cat. no. BML-AK557-0001; Enzo Life Sciences, Inc.) was used to examine SIRT3 enzymatic activity. The osteoblastic cells were treated and lysed with cell lysis buffer (Beyotime Institute of Biotechnology). Lysates were centrifuged at $12,000 \mathrm{x}$ g for $15 \mathrm{~min}$ at $4^{\circ} \mathrm{C}$ and the resulting supernatant was transferred to a new tube. The protein concentrations were determined using a Bradford protein assay kit (Beyotime Institute of Biotechnology). In total, $40 \mathrm{mg}$ protein was incubated at $37^{\circ} \mathrm{C}$ for $45 \mathrm{~min}$ with specific substrates, following the manufacturer's instructions. Then, $25 \mathrm{ml}$ developer was added and samples were incubated for $45 \mathrm{~min}$ at $37^{\circ} \mathrm{C}$. SIRT3 activity was measured using an Infinite M200 microplate reader at the wavelengths 350 and $450 \mathrm{~nm}$.

Immunoprecipitation. Osteoblastic cells were treated with $\mathrm{TiCl}_{4}$ at different concentrations $(0,10,25$ and $50 \mu \mathrm{M})$ at $37^{\circ} \mathrm{C}$ for $24 \mathrm{~h}$ and lysed with cell lysis buffer (Beyotime Institute 
of Biotechnology; cat. no. P0013). Lysates were clarified by centrifugation at $12,000 \mathrm{x} \mathrm{g}$ for $15 \mathrm{~min}$ at $4^{\circ} \mathrm{C}$ and were used for immunoprecipitation. The protein concentrations were determined using a Bradford protein assay kit (Beyotime Institute of Biotechnology). A total of $2 \mu \mathrm{g}$ anti-SOD2 (1:200; Abcam; cat. no. Ab137037) was incubated with 500-1,000 $\mu \mathrm{g}$ protein overnight at $4^{\circ} \mathrm{C}$. This was followed by incubation with $20 \mu 1$ protein A beads (Beyotime Institute of Biotechnology; cat. no. P2006) overnight at $4^{\circ} \mathrm{C}$. After incubation, the beads were washed three times with $\mathrm{PBS}$ and subsequently boiled in $40 \mu \mathrm{l} 1 \mathrm{X}$ sample buffer for $5 \mathrm{~min}$ at $100^{\circ} \mathrm{C}$, and analyzed by western blotting.

Western blotting. Osteoblastic cells were treated at $37^{\circ} \mathrm{C}$ for $24 \mathrm{~h}$ and lysed with cell lysis buffer (Beyotime Institute of Biotechnology; cat. no. P0013). Lysates were clarified by centrifugation at $12,000 \mathrm{x}$ for $15 \mathrm{~min}$ at $4^{\circ} \mathrm{C}$ and the resulting supernatant was transferred to a new tube. The protein concentrations were determined using a Bradford protein assay kit (Beyotime Institute of Biotechnology). The protein samples $(60 \mu \mathrm{g} / \mathrm{lane})$ were separated by SDS-PAGE (12\% gel). Following protein transfer onto PVDF membranes, the membranes were blocked with $20 \mathrm{ml}$ sealing liquid (1 g skimmed milk powder, $20 \mathrm{ml} \mathrm{2 \%} \mathrm{PBS-Tween} \mathrm{20)} \mathrm{on} \mathrm{a}$ horizontal shaker and left to agitate at $25^{\circ} \mathrm{C}$ for $2 \mathrm{~h}$. Then, membranes were incubated overnight at $4^{\circ} \mathrm{C}$ with antibodies against microtubule associated protein 1 light chain $3 \alpha$ (LC3;1:1,000; cat. no. L7543; Sigma-Aldrich; Merck KGaA), SQSTM1/p62 (1:1,000; Abcam; cat. no. ab56416), SIRT3 (1:500; cat. no. sc-99143; Santa Cruz Biotechnology, Inc.), SOD2 (1:1,000; cat. no.sc-33254; Santa Cruz Biotechnology, Inc.), Ac-lysine (1:500; cat. no. Ab137037; Abcam) and GAPDH (1:5,000; cat. no. A5441; Sigma-Aldrich; Merck $\mathrm{KGaA}$ ). The membranes were incubated for $1 \mathrm{~h}$ at $25^{\circ} \mathrm{C}$ with the secondary antibodies, horseradish peroxidase-conjugated affinity-purified goat anti-rabbit $\operatorname{IgG}$ (1:2,000; cat. no. AP132; Sigma-Aldrich; Merck KGaA). Signals were detected using Super Signal West Femto Trial kit (Thermo Fisher Scientific, Inc.). The membranes were exposed to Hyper Performance Chemiluminescence film (GE Healthcare Life Sciences). The relative amount of proteins was quantified using gel analysis software UNSCAN-IT gel (version 5.3; Silk Scientific, Inc.) and normalized to GAPDH internal loading control.

Immunofluorescence. Cells were collected and fixed with4\% paraformaldehyde for $10 \mathrm{~min}$ at room temperature., and subsequently incubated with $0.5 \%$ Triton $\mathrm{X}-100$ at $25^{\circ} \mathrm{C}$ for $20 \mathrm{~min}$. Then, cells were incubated with anti-LC 3(1:200; cat. no. L7543; Sigma-Aldrich; Merck KGaA) overnight at $4^{\circ} \mathrm{C}$ after blocking with 5\% BSA (Gibco; Thermo Fisher Scientific, Inc.) in PBS. After washingwith PBS, the cells were incubated with FITC labeled goat anti-rabbit Immunoglobulin G $(1: 2,000$; cat. no. AP132; Sigma-Aldrich; Merck KGaA) at $25^{\circ} \mathrm{C}$ for 1 hand PI $(50 \mu \mathrm{g} / \mathrm{ml}$; cat. no. C1002; Beyotime Institute of Biotechnology) for $15 \mathrm{~min}$. Then, images (magnification, $\mathrm{x} 1000)$ were captured using a fluorescent microscope (BX51; Olympus Corporation).

Statistical analysis. Data are presented as the mean \pm standard deviation from $\geq 3$ independent experiments. The data were analyzed by one-way ANOVA test using GraphPad Prism-5 software (GraphPad Software, Inc.), followed by Tukey's test for multiple comparisons using SPSS (v.10.01; IBM Corp.). $\mathrm{P}<0.05$ was considered to indicate a statistically significant difference.

\section{Results}

Ti ions can lead to osteoblastic cellular damage via autophagy. To determine whether Ti ions can damage osteoblastic cells, the present study established a cellular model. It was found that $\mathrm{Ti}$ ion exposure decreased osteoblastic cell viability in a dose-dependent manner (Fig. 1A). To investigate whether autophagy is involved in osteoblast injury caused by Ti ions, the expression level of LC3II was assessed as a marker of autophagy in osteoblastic cells exposed to Ti ions. The present results suggested that the protein expression level of LC3II increased, while the expression level of sequestosome 1(P62) decreased with increasing Ti ion dosage (Fig. 1B). The present study also examined osteoblastic cells by fluorescence microscopy, and found a significant increase in autophagy in $\mathrm{TiCl}_{4}$ group (Fig. 1C).

The basal level of autophagy has a protective effect on cells, but excessive autophagy can induce autophagic cell death. To investigate the effects of autophagy on osteoblastic cells caused by $\mathrm{Ti}$ ions, the apoptotic rate of osteoblastic cells treated with Ti ions was examined. No significant rate of apoptosis of osteoblastic cells was identified (data not shown). In addition, osteoblasts were treated with Bafilomycin A1 (BafA1), an autophagic inhibitor of the proton pump of autophagic lysosomes that can inhibit the activity of autophagosomes and reduce their degradation (19). After treatment with BafA1, the expression level of LC3II increased in the osteoblasts (Fig. 1C and D), suggesting that enhanced LC3II after $\mathrm{Ti}$ ion exposure increased the autophagic flow. In addition, it was found that cell viability improved after treatment with BafA1 compared with $\mathrm{TiCl}_{4}$ group (Fig. 1E).

Ti ions increase autophagy via mROS. Autophagy has been shown to be related to mROS (20). The initial oxygen reduction product in mitochondria is $\mathrm{O}_{2}$, which is then rapidly converted to $\mathrm{H}_{2} \mathrm{O}_{2}$ (21). Therefore, the present study investigate the levels of mROS in osteoblasts treated with Ti ions, and identified significantly elevated of mROS levels in these cells (Fig. 2A). Furthermore, osteoblastic cells were pretreated with the mitochondrial antioxidant, Mito-TEMPO, which targets SOD2 in mitochondria, for $2 \mathrm{~h}$ before co-culture with Ti ions. It was demonstrated that Mito-TEMPO inhibited the production of mROS (Fig. 2B), and it inhibited the expression level of LC3II caused by Ti ions (Fig. 2C). Moreover, the viability of osteoblastic cells was significantly increased by pretreatment with Mito-TEMPO compared with $\mathrm{TiCl}_{4}$ group (Fig. 2D). Collectively, these results suggested that oxidative stress induced by Ti ions triggers autophagy, while antioxidants, such as Mito-TEMPO, can mitigate mitochondrial oxidative stress and reduce this excess autophagy.

Ti ions can increase SOD2 acetylation by inhibiting SIRT3 expression and activity. SOD2 is the main scavenger of oxygen free radicals in mitochondria (22). SOD2 catalyzes the conversion of $\mathrm{O}_{2} \cdot$ to $\mathrm{H}_{2} \mathrm{O}_{2}$ and plays an important role in regulating 

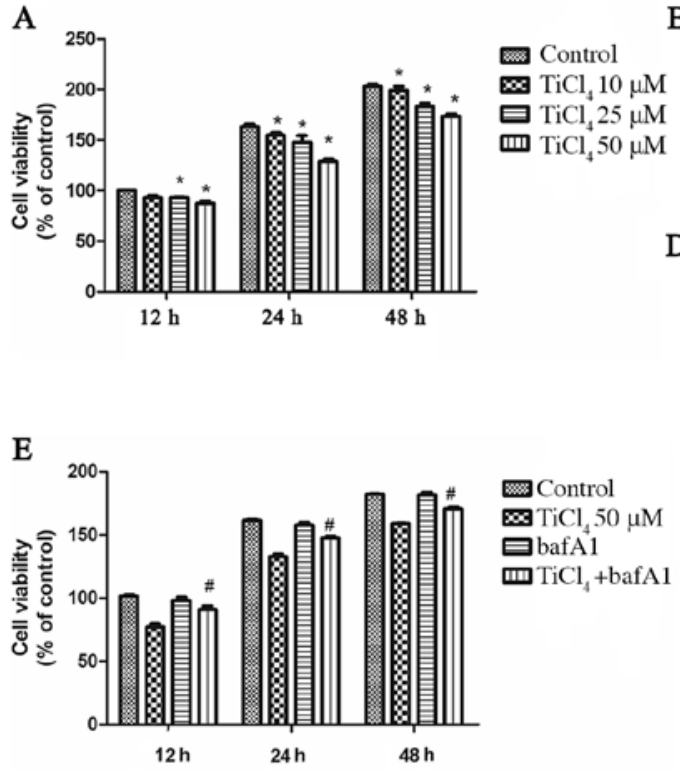

B
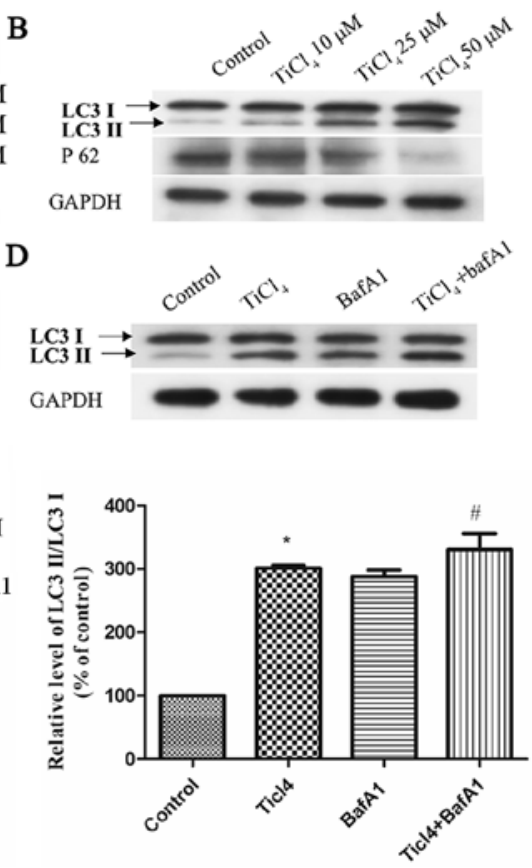

C Control

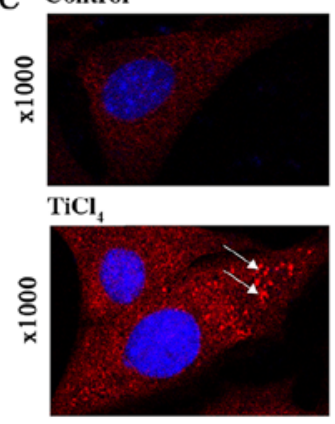

bafA1

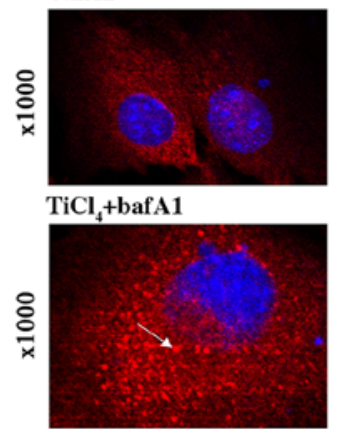

Figure 1. Ti ions can lead to autophagic cell death in osteoblastic cells. (A) Ti ion exposure decreased the viability of osteoblasts in a dose dependent manner. (B) Representative immunoblot analysis of LC3 and P62 assayed after osteoblast exposure to Ti ions at different concentrations. GAPDH was used as an internal standard for protein loading. (C) Fluorescence microscopy indicated an increased number of autophagic vacuoles in cells incubated with $50 \mu \mathrm{M} \mathrm{TiCl}_{4}$, in the absence or presence of $10 \mathrm{nM}$ BafA1 for $24 \mathrm{~h}$. Osteoblastic cells were incubated with $50 \mu \mathrm{M}$ Ti ions, in the absence or presence of $10 \mathrm{nM}$ BafA1 for $24 \mathrm{~h}$. (D) Protein expression level of LC3-II was quantified by normalization of densitometry to GAPDH. (E) Cell viability was increased in the presence of 10 nM BafA1. Data are presented as a percentage of the control group, which was set at $100 \%$. ${ }^{*} \mathrm{P}<0.05$ vs. control group, ${ }^{\sharp} \mathrm{P}<0.05$ vs. TiCl ${ }_{4}$ group. $\mathrm{Ti}$, titanium; $\mathrm{TiCl}_{4}$, Ti tetrachloride; BafA1, Bafilomycin A1; LC3, microtubule associated protein 1 light chain $3 \alpha$; P62, sequestosome 1.

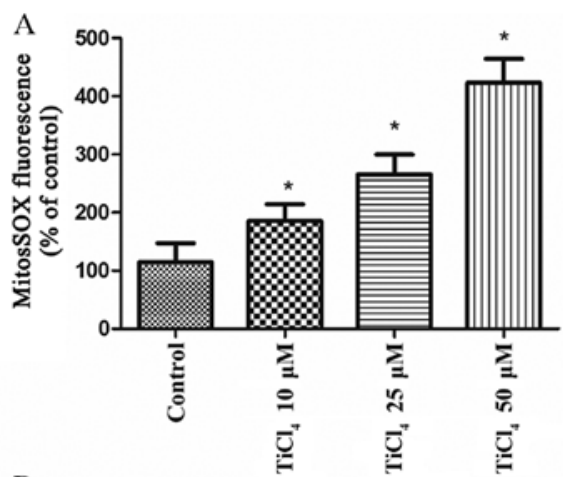

$\mathrm{B}$

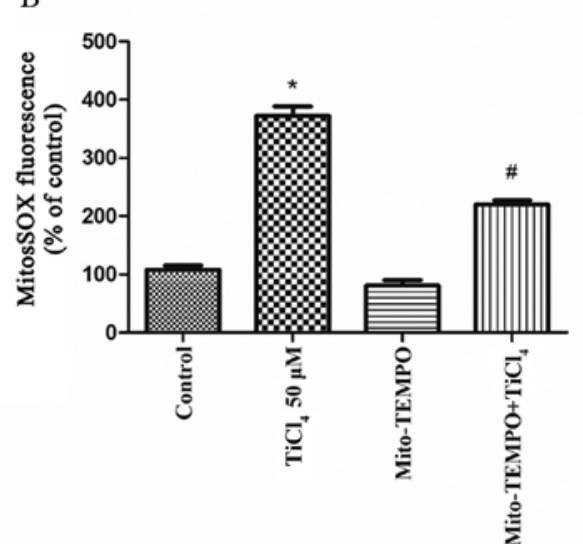

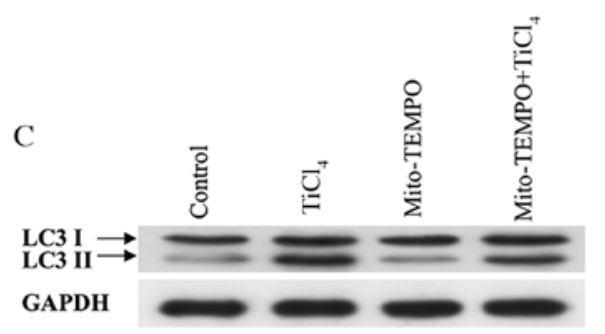

Control

D

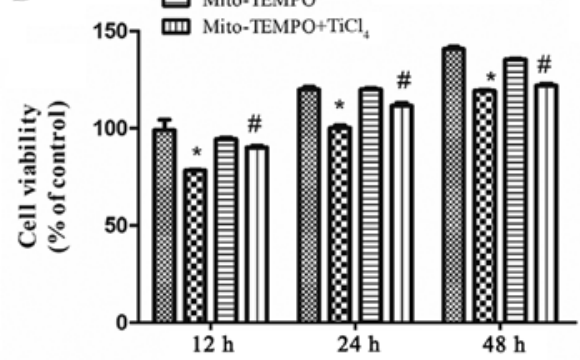

Figure 2. mROS mediates Ti ion induced autophagy in osteoblastic cells. (A) Quantification of mROS levels using a fluorescence spectrometer after osteoblastic cells were treated with $\mathrm{TiCl}_{4}$. Osteoblastic cells were preincubated with $10 \mathrm{mM}$ Mito-TEMPO for $2 \mathrm{~h}$ and treated with $50 \mu \mathrm{M} \mathrm{TiCl}{ }_{4}$, then the(B) $\mathrm{mROS}$ levels, (C) LC3 protein expression level and (D) and cell viability were determined. Data are presented as a percentage of the control group, which was set at

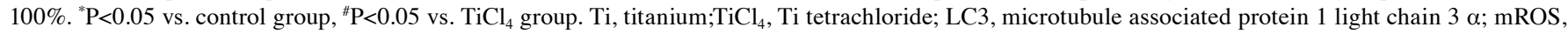
mitochondrion-derived reactive oxygen species. 
A

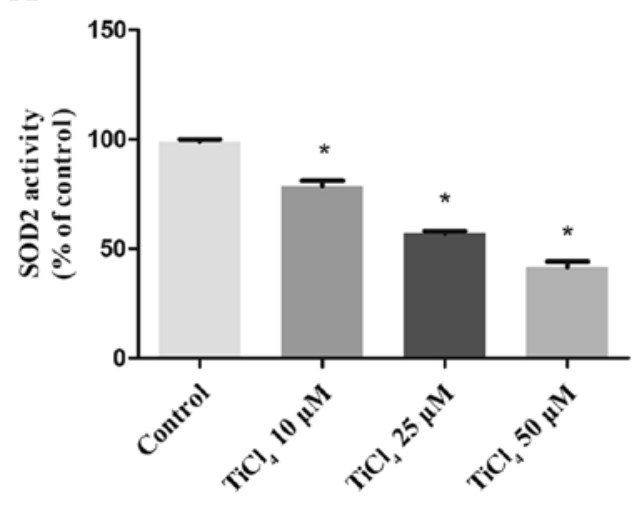

B
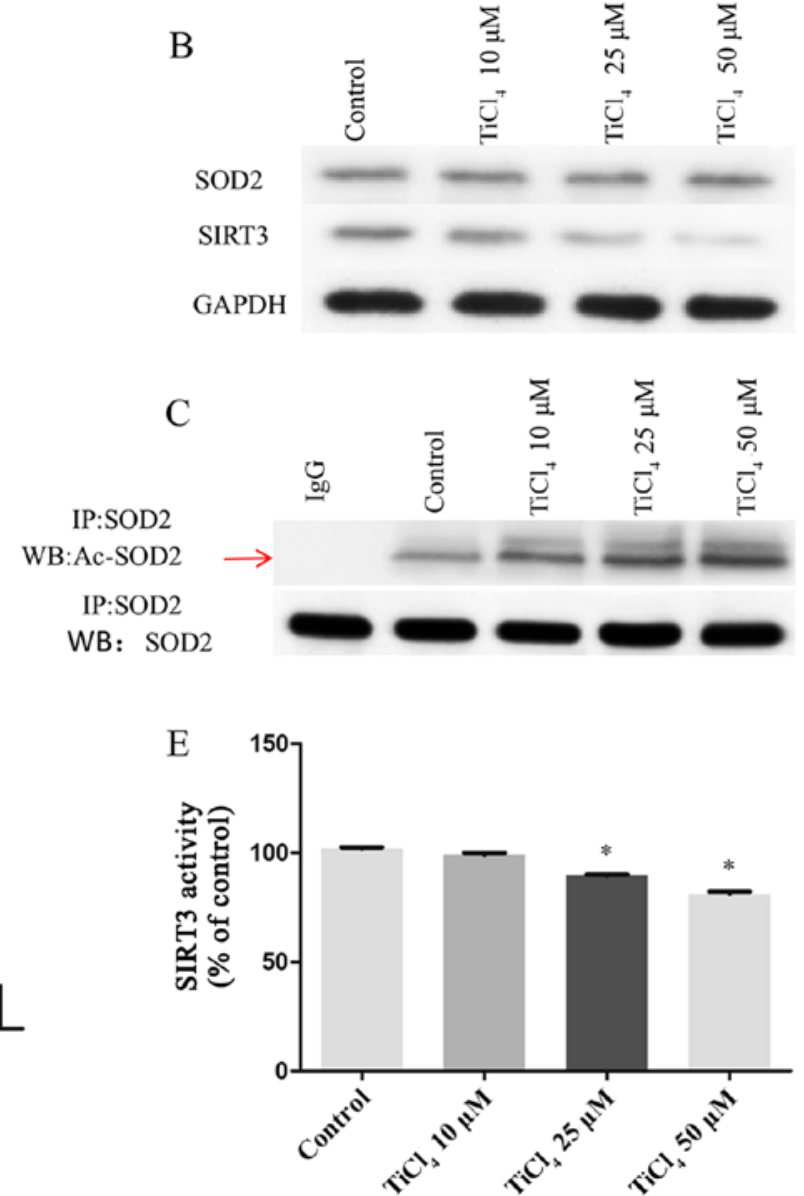

Figure 3. Ti ions can increase acetylated-SOD2 expression level, and decrease SIRT3 protein expression level and activity in a dose-dependent manner. (A) SOD2 activity in osteoblastic cells exposed to $\mathrm{TiCl}_{4}$. (B) Representative immunoblot of SOD2 and SIRT3 protein expression levels in osteoblastic cells. GAPDH was used as an internal standard. (C) Acetylation of SOD2 after $\mathrm{TiCl}_{4}$ exposure was determined by immunoprecipitation with an anti-SOD2 antibody, followed by immunoblot analysis of acetylated-lysine. GAPDH used as an internal standard for protein loading. (D) Reverse transcription-quantitative PCR was used to detect SIRT3 mRNA expression levels. (E) SIRT3 activity level. Data are presented as a percentage of the control group, which is set at $100 \%$. ${ }^{*} \mathrm{P}<0.05$ vs. control group. Ti, titanium; SOD2, superoxide dismutase 2; SIRT3, sirtuin 3; $\mathrm{TiCl}_{4}, \mathrm{Ti}$ tetrachloride.

mROS in mitochondria (22). Therefore, the present study examined the effects of Ti ions on SOD2 expression levels. It was demonstrated that the activity of SOD2 decreased with increasing Ti ion dose (Fig. 3A), but no effect was observed on the protein expression levels of SOD2 (Fig. 3B). SOD2 activity is regulated by the acetylation of lysine residues (22-24). Therefore, the present study detected the acetylation level of SOD2 by coimmunoprecipitation and western blotting. It was found that $\mathrm{Ti}$ ion exposure resulted in a progressive increase in SOD2 acetylation level (Fig. 3C). Deacetylation of SOD2 is mainly regulated by the mitochondrial deacetylase SIRT3 (25-27). Therefore, the present study investigated SIRT3 activity and its concentration in osteoblastic cells treated with Ti ions. The present results suggested that Ti ions caused a significant decrease in the mRNA (Fig. 3D) and protein (Fig. 3B) expression levels of SIRT3 in a dose-dependent manner. The present results also indicated that the levels of SIRT3 activity in the Ti ion group were significantly lower compared with the control group (Fig. 3E).

SIRT3 and SOD2 modulate Ti ion-induced mROS accumulation and autophagy. To examine whether the recovery of SIRT3 protein expression level or activity could prevent autophagy induced by Ti ion exposure, the present study transfected SIRT3 into osteoblastic cells to overexpress SIRT3. It was demonstrated that overexpression of SIRT3 ameliorated the inhibition of SIRT3 activity induced by Ti ions, reduced the acetylation of SOD2 (Fig. 4A) and increased the activity of SOD2 (Fig. 4B). Furthermore, SIRT3 overexpression significantly reduced the level of mROS produced by Ti ions (Fig. 4C). The present results also suggested that the overexpression of SIRT3 increased cell viability and significantly reduced the expression levels of LC3II in Ti ion treated cells (Fig. 4A and D).

\section{Discussion}

Ti is used extensively in dental implants. However, clinical studies have found that Ti particles released from Ti implants can lead to aseptic loosening of orthopedic implants $(28,29)$. The corrosive properties of Ti are increased in low dissolved-oxygen conditions such as in the oral cavity, and especially in the presence of small amounts of fluoride $(8,30,31)$. During implant placement, increasing osteoblast adhesion and proliferation on a Ti surface is essential for successful osseointegration (32). The osseointegration process can be divided into hemostasis, inflammatory, proliferation and a remodeling phase (33). In the inflammatory phase, infiltrated inflammatory cells synthe- 

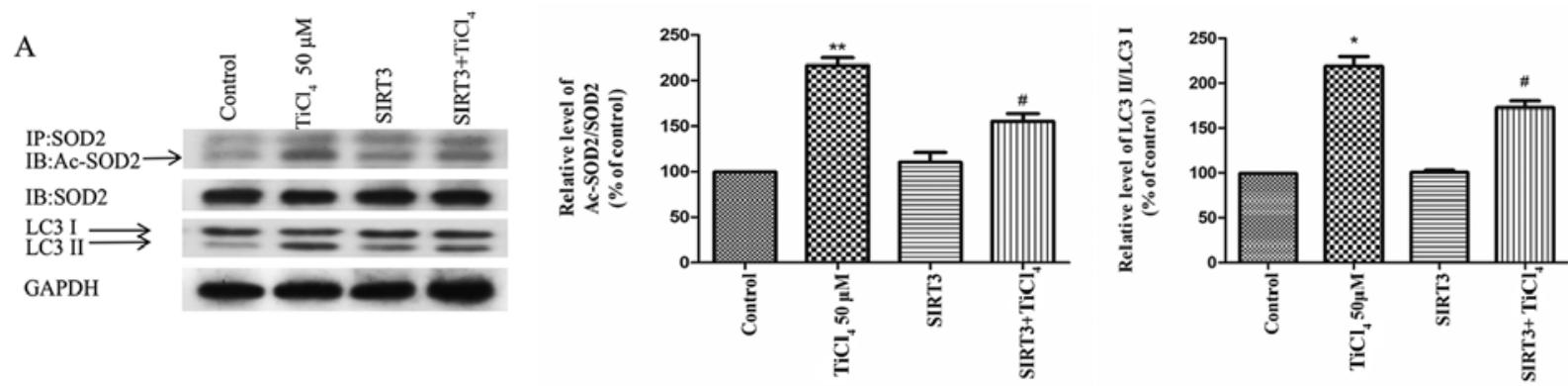

B

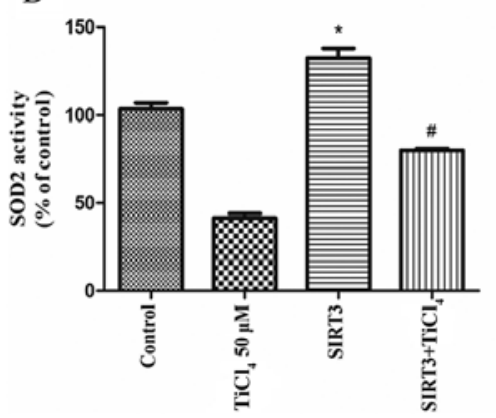

C

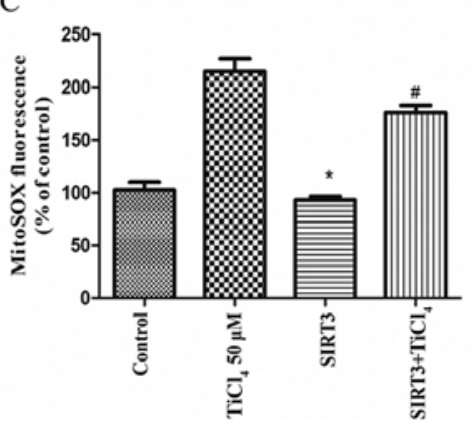

D

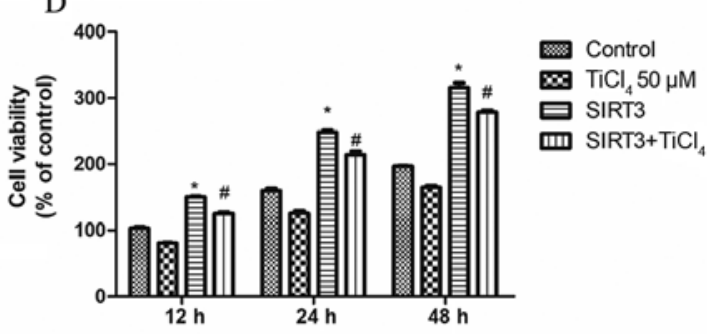

Figure 4. SIRT3 and SOD2 modulate Ti ion induced mROS accumulation and autophagy in osteoblastic cells. (A) SIRT3 overexpression induced deacetylation of SOD2 after $50 \mu \mathrm{M} \mathrm{TiCl}_{4}$ exposure. Representative immunoblot of LC3 protein levels in osteoblastic cells. GAPDH used as an internal standard for protein loading. (B) SOD2 activity in osteoblastic cells. (C) mROS production in osteoblastic cells. (D) Cell viability. Data are presented as a percentage of the control group, which was set at $100 \%$. ${ }^{*} \mathrm{P}<0.05$ vs. control group, ${ }^{*} \mathrm{P}<0.05 \mathrm{vs}$. $\mathrm{TiCl}_{4}$ group.ac-SOD2, acetylated superoxide dismutase 2 ; Ti, titanium; $\mathrm{TiCl}{ }_{4}, \mathrm{Ti}$ tetrachloride; SIRT3, sirtuin 3; LC3, microtubule associated protein 1 light chain $3 \alpha$; mROS, mitochondrial reactive oxygen species.

size and secrete ROS (34). Furthermore, Ti ions released from metal graft material can stimulate ROS synthesis (35). This overproduction of ROS can result in failure of implant placement by reducing osseointegration via dysfunction and apoptosis of the osteoblasts (36). N-acetyl-cysteine, a potent ROS inhibitor, enhances osseointegration by scavenging ROS in osteoblasts on the Ti alloy surface (37). Moreover, insulin improves the impaired osteogenesis of osteoblasts on the Ti surface by inhibiting ROS overproduction (38). In contrast to previous studies $(35,37,38)$, the present results suggested that Ti ions could lead to the production of ROS via the mitochondrial pathway. Instead of apoptotic cell death (36), the present results suggested that ROS could lead to the autophagic death of osteoblasts.

By removing cells damaged by intracellular pathogens and toxic metabolites, autophagy aids in cell survival (39). However, autophagy may cause cell death via the degradation of essential cellular constituents and excessive self-digestion (40). The present results indicated that Ti ion induced increases in LC3 expression may be due to an elevation of autophagic flux. In addition, it was demonstrated that $\mathrm{Ti}$ ion exposure decreased the viability of osteoblasts. Collectively, the present results suggested that autophagy may contribute to Ti ion-mediated osteoblast damage in the periodontium.

Increased generation of ROS is an important stimulus of autophagy in several diseases (41-45). It is reported that autophagic removal and degradation of damaged proteins caused by mitochondrial oxidative stress is beneficial for cell survival (46). However, excessive amounts of ROS and severe oxidative stress may activate signaling pathways, and cause autophagic cell death $(20,47)$. The present results suggested that $\mathrm{Ti}$ ion exposure promoted mROS 2-fold compared with the control group. Moreover, Mito-TEMPO treatment, the mitochondrial-targeted SOD mimetic, reduced oxidative stress and decreased autophagic cell death, suggesting that mROS accumulation is an important mechanism underlying the sensitization of cells to autophagy.

Although mitochondrial oxidative stress is associated with autophagy (48), the molecular mechanism of oxygen free radical aggregation from mitochondria is not fully understood. Cells can regulate oxygen free radicals derived from mitochondria via a specific mechanism (47). Furthermore, mitochondria have a special function of removing oxygen free radicals from mitochondria to maintain homeostasis (49). Mitochondria consume $90 \%$ of intracellular oxygen, so SOD2 activity is important in maintaining the balance of oxygen free radicals derived from mitochondria $(23,50)$. SOD 2 is an enzyme that scavenges free radicals, and is only found in mitochondria $(51,52)$. However, in the present study, it was found that the protein expression of SOD2 was not affected by $\mathrm{Ti}$ ion treatment. The amount of SOD2 protein is regulated by transcription, and its activity is regulated by acetylation level $(23,24,50)$. Consistent with previous studies $(53,54)$, $\mathrm{Ti}$ ion exposure in the present study resulted in an elevated level of acetylation of SOD2 in a dose-dependent manner. Therefore, the present results suggested that Ti ions increased mitochondrial oxygen free radicals by increasing SOD2 acetylation levels, rather than by decreasing SOD2 protein expression levels.

Lysine acetylation is an important post-translational modification for the regulation of mitochondrial proteins and autophagy (55-57). In total, three deacetylases SIRT3, SIRT4 and SIRT5, are found in mitochondria. SIRT3 is the strongest deacetylase in mitochondria, and is directly involved 
in mitochondrial energy synthesis and the control of oxygen free radical levels $(47,58)$. Moreover, SIRT3 controls SOD2 activity by regulating the acetylation level of SOD2, and its target lysine has been identified (59). SIRT3 deacetylates SOD2 in response to ionizing radiation, indicating that SOD2 is a major downstream signal of SIRT3-mediated mitochondrial derived $\mathrm{O}_{2}$ reduction $(24,47)$.The present results indicated that $\mathrm{Ti}$ ions did not decrease SOD2 expression levels, but increased acetylation levels. Furthermore, it was demonstrated that SIRT3 expression level and activity were decreased. It was also found that SIRT3 overexpression could repair the increase inSOD2 acetylation caused by $\mathrm{Ti}$ ions, reduce the acetylation of SOD2 and increase SOD2 activity, thus maintaining the stability of mitochondrial oxygen free radicals and reversing autophagy induced by $\mathrm{Ti}$ ions. Therefore, SIRT3/SOD2 mediated autophagy may be an important mechanism of osteoblastic cells damage induced by $\mathrm{Ti}$ ions.

In conclusion, the present results suggested that there is a dose-response relationship between $\mathrm{Ti}$ ions and osteoblastic cells damage. Furthermore, increased autophagy-induced by mROS may be one of the important factors of Ti ion-induced osteoblastic cell damage. Moreover, Ti ions may lead to the dysfunction of SIRT3 and SOD2 in mitochondria. Therefore, inhibition of SIRT3 activity is an important mechanism of osteoblastic cellular damage induced by Ti ion exposure.

\section{Acknowledgements}

Not applicable.

\section{Funding}

No funding was received.

\section{Availability of data and materials}

The datasets used and/or analyzed during the present study are available from the corresponding author on reasonable request.

\section{Authors' contributions}

$\mathrm{JM}$ and XX contributed to the concept and the design of the study. SW, JY and TL performed research. SH acquired the data and performed statistical analysis. SW and JY drafted the manuscript. XX revised the manuscript. All authors read and approved the final manuscript

\section{Ethics approval and consent to participate}

Not applicable.

\section{Patient consent for publication}

Not applicable.

\section{Competing interests}

The authors declare that they have no competing interests.

\section{References}

1. Anselme K: Osteoblast adhesion on biomaterials. Biomaterials 21: 667-681, 2000.

2. Anselme K: Biomaterials and interface with bone. Osteoporos Int 22: 2037-2042, 2011.

3. Davies JE: Mechanisms of endosseous integration. Int J Prosthodont 11: 391-401, 1998.

4. Davies JE: Understanding peri-implant endosseous healing. J Dent Educ 67: 932-949, 2003.

5. Hermann JS, Buser D, Schenk RK, Schoolfield JD and Cochran DL: Biologic Width around one- and two-piece titanium implants. Clin Oral Implants Res 12: 559-571, 2001.

6. Lindhe J and Meyle J; Group D of European Workshop on Periodontology: Peri-implant diseases: Consensus Report of the Sixth European Workshop on Periodontology. J Clin Periodontol 35 (Suppl): 282-285, 2008.

7. Brånemark PI, Adell R, Albrektsson T, Lekholm U, Lundkvist S and Rockler B: Osseointegrated titanium fixtures in the treatment of edentulousness. Biomaterials 4: 25-28, 1983.

8. Wachi T, Shuto T, Shinohara Y, Matono Y and Makihira S: Release of titanium ions from an implant surface and their effect on cytokine production related to alveolar bone resorption. Toxicology 327: 1-9, 2015.

9. Schwarz F, Sahm N, Mihatovic I, Golubovic V and Becker J: Surgical therapy of advanced ligature-induced peri-implantitis defects: Cone-beam computed tomographic and histological analysis. J Clin Periodontol 38: 939-949, 2011.

10. Kumazawa R, Watari F, Takashi N, Tanimura Y, Uo M and Totsuka Y: Effects of Ti ions and particles on neutrophil function and morphology. Biomaterials 23: 3757-3764, 2002.

11. Wennerberg A, Ide-Ektessabi A, Hatkamata S, Sawase T, Johansson C, Albrektsson T, Martinelli A, Södervall U and Odelius H: Titanium release from implants prepared with different surface roughness. Clin Oral Implants Res 15: 505-512, 2004.

12. Ellingsen JE, Johansson CB, Wennerberg A and Holmén A: Improved retention and bone-tolmplant contact with fluoride-modified titanium implants. Int J Oral Maxillofac Implants 19: 659-666, 2004.

13. Pajarinen J, Kouri VP, Jämsen E, Li TF, Mandelin J and Konttinen YT: The response of macrophages to titanium particles is determined by macrophage polarization. Acta Biomater 9: 9229-9240, 2013.

14. Obando-Pereda GA, Fischer L and Stach-Machado DR: Titanium and zirconia particle-induced pro-inflammatory gene expression in cultured macrophages and osteolysis, inflammatory hyperalgesia and edema in vivo. Life Sci 97: 96-106, 2014.

15. Brettin BT, Grosland NM, Qian F, Southard KA, Stuntz TD, Morgan TA, Marshall SD and Southard TE: Bicortical vs monocortical orthodontic skeletal anchorage. Am J Orthod Dentofacial Orthop 134: 625-635, 2008.

16. Bitar D and Parvizi J: Biological response to prosthetic debris. World J Orthop 6: 172-189, 2015.

17. Grunow M and Schöpp W: [Determination of the activity of superoxide dismutase in terms of rea substrate conversion]. Biomed Biochim Acta 48: 185-199, 1989 (In German).

18. Livak KJ and Schmittgen TD: Analysis of relative gene expression data using real-time quantitative PCR and the 2(-Delta Delta C(T)) Method. Methods 25: 402-408, 2001.

19. Klionsky DJ, Elazar Z, Seglen PO and Rubinsztein DC: Does bafilomycin A1 block the fusion of autophagosomes with lysosomes? Autophagy 4: 849-850, 2008.

20. Sena LA and Chandel NS: Physiological roles of mitochondrial reactive oxygen species. Mol Cell 48: 158-167, 2012.

21. Lambert AJ and Brand MD: Reactive oxygen species production by mitochondria. Methods Mol Biol 554: 165-181, 2009.

22. Tao R, Vassilopoulos A, Parisiadou L, Yan Y and Gius D: Regulation of MnSOD enzymatic activity by Sirt3 connects the mitochondrial acetylome signaling networks to aging and carcinogenesis. Antioxid Redox Signal 20: 1646-1654, 2014.

23. Chen Y, Zhang J, Lin Y, Lei Q, Guan KL, Zhao S and Xiong Y: Tumour suppressor SIRT3 deacetylates and activates manganese superoxide dismutase to scavenge ROS. EMBO Rep 12: 534-541, 2011.

24. Tao R, Coleman MC, Pennington JD, Ozden O, Park SH, Jiang H, Kim HS, Flynn CR, Hill S, Hayes McDonald W, et al: Sirt3-mediated deacetylation of evolutionarily conserved lysine 122 regulates MnSOD activity in response to stress. Mol Cell 40: 893-904, 2010 
25. Di Tucci AA, Murru R, Alberti D, Rabault B, Deplano S and Angelucci E: Correction of anemia in a transfusion-dependent patient with primary myelofibrosis receiving iron chelation therapy with deferasirox (Exjade, ICL670). Eur J Haematol 78: 540-542, 2007.

26. Messa E, Cilloni D, Messa F, Arruga F, Roetto A and Saglio G Deferasirox treatment improved the hemoglobin level and decreased transfusion requirements in four patients with the myelodysplastic syndrome and primary myelofibrosis. Acta Haematol 120: 70-74, 2008.

27. Angelucci E, Santini V, Di Tucci AA, Quaresmini G, Finelli C, Volpe A, Quarta G, Rivellini F, Sanpaolo G, Cilloni D, et al: Deferasirox for transfusion-dependent patients with myelodysplastic syndromes: Safety, efficacy, and beyond (GIMEMA MDS0306 Trial). Eur J Haematol 92: 527-536, 2014.

28. Jacobs JJ, Gilbert JL and Urban RM: Corrosion of metal orthopaedic implants. J Bone Joint Surg Am 80: 268-282, 1998.

29. Gallo J, Kamínek P, Tichá V, Riháková P and Ditmar R: Particle disease. A comprehensive theory of periprosthetic osteolysis: A review. Biomed Pap Med Fac Univ Palacky Olomouc Czech Repub 146: 21-28, 2002.

30. Nakagawa M, Matsuya S and Udoh K: Effects of fluoride and dissolved oxygen concentrations on the corrosion behavior of pure titanium and titanium alloys. Dent Mater J 21: 83-92, 2002.

31. Matono Y, Nakagawa M, Matsuya S, Ishikawa K and Terada Y: Corrosion behavior of pure titanium and titanium alloys in various concentrations of Acidulated Phosphate Fluoride (APF) solutions. Dent Mater J 25: 104-112, 2006.

32. Roehlecke C, Witt M, Kasper M, Schulze E, Wolf C, Hofer A and Funk RW: Synergistic effect of titanium alloy and collagen type I on cell adhesion, proliferation and differentiation of osteoblast-like cells. Cells Tissues Organs 168: 178-187, 2001.

33. Terheyden $\mathrm{H}$, Lang NP, Bierbaum S and Stadlinger B Osseointegration--communication of cells. Clin Oral Implants Res 23: 1127-1135, 2012.

34. Rajendrakumar SK, Revuri V, Samidurai M, Mohapatra A,Lee JH, Ganesan P, Jo J, Lee YK and Park IK: Peroxidase-mimicking nanoassembly mitigates lipopolysaccharide-induced endotoxemia and cognitive damage in the brain by impeding inflammatory signaling in macrophages. Nano Lett 18: 6417-6426, 2018

35. Landgraeber S, Jäger M, Jacobs JJ and Hallab NJ: The pathology of orthopedic implant failure is mediated by innate immune system cytokines. Mediators Inflamm 2014: 185150, 2014.

36. Li X, Ma XY, Feng YF, Ma ZS, Wang J, Ma TC, Qi W, Lei W and Wang L: Osseointegration of chitosan coated porous titanium alloy implant by reactive oxygen species-mediated activation of the PI3K/AKT pathway under diabetic conditions. Biomaterials 36: 44-54, 2015.

37. Feng YF, Wang L, Zhang Y, Li X, Ma ZS, Zou JW, Lei W and Zhang ZY: Effect of reactive oxygen species overproduction on osteogenesis of porous titanium implant in the present of diabetes mellitus. Biomaterials 34: 2234-2243, 2013.

38. Wang L, Zhao X, Wei BY, Liu Y, Ma XY, Wang J, Cao PC Zhang Y, Yan YB, Lei W, et al: Insulin improves osteogenesis of titanium implants under diabetic conditions by inhibiting reactive oxygen species overproduction via the PI3K-Akt pathway. Biochimie 108: 85-93, 2015.

39. Klionsky DJ, Abdelmohsen K, Abe A, Abedin MDJ, Abeliovich $\mathrm{H}$ Arozena AA, Adachi H, Adams CM, Adams PD, Adeli K, et al: Guidelines for the use and interpretation of assays for monitoring autophagy (3rd edition). Autophagy 12: 1-222, 2016.

40. Liu Y and Levine B: Autosis and autophagic cell death: The dark side of autophagy. Cell Death Differ 22: 367-376, 2015.

41. Essick EE and Sam F: Oxidative stress and autophagy in cardiac disease, neurological disorders, aging and cancer. Oxid Med Cell Longev 3: 168-177, 2010.

42. Zhang T, Li Y, Park KA, Byun HS, Won M, Jeon J, Lee Y, Seok JH, Choi SW, Lee SH, et al: Cucurbitacin induces autophagy through mitochondrial ROS production which counteracts to limit caspase-dependent apoptosis. Autophagy 8: 559-576, 2012.
43. Shen W, Tian C, Chen H, Yang Y, Zhu D, Gao P and Liu J: Oxidative stress mediates chemerin-induced autophagy in endothelial cells. Free Radic Biol Med 55: 73-82, 2013.

44. Dai DF and Rabinovitch P: Mitochondrial oxidative stress mediates induction of autophagy and hypertrophy in angiotensin-II treated mouse hearts. Autophagy 7: 917-918, 2011

45. Kim Y, Kim YS, Kim DE, Lee JS, Song JH, Kim HG, Cho DH, Jeong SY, Jin DH, Jang SJ, et al: BIX-01294 induces autophagy-associated cell death via EHMT2/G9a dysfunction and intracellular reactive oxygen species production. Autophagy 9: 2126-2139, 2013

46. Liang Q, Benavides GA, Vassilopoulos A, Gius D, Darley-Usmar V and Zhang J: Bioenergetic and autophagic control by Sirt3 in response to nutrient deprivation in mouse embryonic fibroblasts. Biochem J 454: 249-257, 2013.

47. Pi H, Xu S, Reiter RJ, Guo P, Zhang L, Li Y, Li M, Cao Z, Tian L, Xie J, et al: SIRT3-SOD2-mROS-dependent autophagy in cadmium-induced hepatotoxicity and salvage by melatonin. Autophagy 11: 1037-1051, 2015.

48. Lee J, Giordano S and Zhang J: Autophagy, mitochondria and oxidative stress: Cross-talk and redox signalling. Biochem J 441: 523-540, 2012.

49. Zorov DB, Juhaszova M and Sollott SJ: Mitochondrial reactive oxygen species (ROS) and ROS-induced ROS release. Physiol Rev 94: 909-950, 2014.

50. Zhu Y, Park SH, Ozden O, Kim HS, Jiang H, Vassilopoulos A, Spitz DR and Gius D: Exploring the electrostatic repulsion model in the role of Sirt3 in directing MnSOD acetylation status and enzymatic activity. Free Radic Biol Med 53: 828-833, 2012

51. Zeng L, Yang Y, Hu Y, Sun Y, Du Z, Xie Z, Zhou T and Kong W: Age-related decrease in the mitochondrial sirtuin deacetylase Sirt3 expression associated with ROS accumulation in the auditory cortex of the mimetic aging rat model. PLoS One 9: e88019, 2014.

52. Li M, Chiu JF, Mossman BT and Fukagawa NK: Down-regulation of manganese-superoxide dismutase through phosphorylation of FOXO3a by Akt in explanted vascular smooth muscle cells from old rats. J Biol Chem 281: 40429-40439, 2006.

53. Niska K, Pyszka K, Tukaj C, Wozniak M, Radomski MW and Inkielewicz-Stepniak I: Titanium dioxide nanoparticles enhance production of superoxide anion and alter the antioxidant system in human osteoblast cells. Int J Nanomedicine 10: 1095-1107, 2015.

54. Li Y, Wang W, Wu Q, Li Y, Tang M, Ye B and Wang D: Molecular control of $\mathrm{TiO}_{2}$-NPs toxicity formation at predicted environmental relevant concentrations by Mn-SODs proteins. PLoS One 7: e44688, 2012.

55. Bánréti A, Sass M and Graba Y: The emerging role of acetylation in the regulation of autophagy. Autophagy 9: 819-829, 2013.

56. Papanicolaou KN, O'Rourke B and Foster DB: Metabolism leaves its mark on the powerhouse: Recent progress in post-translational modifications of lysine in mitochondria. Front Physiol 5: 301, 2014.

57. Hebert AS, Dittenhafer-Reed KE, Yu W, Bailey DJ, Selen ES, Boersma MD, Carson JJ, Tonelli M, Balloon AJ, Higbee AJ, et al: Calorie restriction and SIRT3 trigger global reprogramming of the mitochondrial protein acetylome. Mol Cell 49: 186-199, 2013.

58. Giralt A and Villarroya F: SIRT3, a pivotal actor in mitochondrial functions: Metabolism, cell death and aging. Biochem J 444: $1-10,2012$.

59. Kim H, Lee YD, Kim HJ, Lee ZH and Kim HH: SOD2 and Sirt3 Control Osteoclastogenesis by Regulating Mitochondrial ROS. J Bone Miner Res 32: 397-406, 2017.

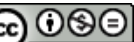

This work is licensed under a Creative Commons Attribution-NonCommercial-NoDerivatives 4.0 International (CC BY-NC-ND 4.0) License. 